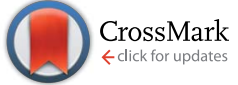

Cite this: J. Mater. Chem. A, 2015, 3, 13699

Received 3rd April 2015

Accepted 18th May 2015

DOI: $10.1039 / c 5 t a 02440 d$

www.rsc.org/MaterialsA

\section{Synthesis of ultralong MnO/C coaxial nanowires as freestanding anodes for high-performance lithium ion batteries $\uparrow$}

\begin{abstract}
Jian-Gan Wang, ${ }^{a}$ Cunbao Zhang, ${ }^{a}$ Dandan Jin, ${ }^{a}$ Keyu Xie ${ }^{a}$ and Bingqing Wei ${ }^{\star a b}$
A facile synthesis strategy is reported for the preparation of a freestanding membrane of ultralong $\mathrm{MnO} / \mathrm{C}$ coaxial nanowires using a novel in situ interfacial polymerization technique. The $\mathrm{MnO} / \mathrm{C}$ membrane possesses interconnected porous structures with a nanowire diameter of ca. $100 \mathrm{~nm}$ and a length of up to hundreds of micrometers. When used as a freestanding anode for lithium ion batteries, the coaxial $\mathrm{MnO} / \mathrm{C}$ nanocomposites exhibit a high reversible capacity of $832 \mathrm{~mA} \mathrm{~h} \mathrm{~g}^{-1}$ at a current density of $100 \mathrm{~mA} \mathrm{~g}^{-1}$ after 100 cycles, good rate capability and outstanding cycling stability with a specific capacity of $480 \mathrm{~mA} \mathrm{~h} \mathrm{~g}{ }^{-1}$ being retained after 600 cycles at a high current density of $1000 \mathrm{~mA} \mathrm{~g}^{-1}$. The uniform carbon coating formed along the ultralong one-dimensional nanostructure surface is the keyenabling factor that not only improves the electrode reaction kinetics, but also renders excellent cycling performance by accommodating the large volume variation of $\mathrm{MnO}$ during charge/discharge processes. The superior electrochemical properties suggest that the facile synthesis strategy can be extended to the fabrication of other freestanding films for potential application in energy storage systems.
\end{abstract}

\section{Introduction}

Rechargeable lithium ion batteries (LIBs) have received significant attention in science and technology communities due to their high energy density, long cycle life and no memory effect. $^{{ }^{-3}}$ In recent decades, LIBs have been exploited for various applications ranging from portable electronic devices to electric vehicles and smart grids. With the increasing demands for higher energy and power density, extensive efforts have been devoted to developing new electrode materials with higher specific capacity, better rate capability and long-term cyclability. Transition metal oxides, such as $\mathrm{CoO}_{x}, \mathrm{NiO}, \mathrm{FeO}_{x}, \mathrm{MnO}_{x}$, etc. have become promising alternatives to the commercial graphite anode because of their much higher lithium-storage capacity, which makes them a research focus for high-performance LIBs. $^{4-6}$

Among the above-mentioned potential candidates, $\mathrm{MnO}_{x}$ (i.e., $\mathrm{MnO}, \mathrm{MnO}_{2}, \mathrm{Mn}_{2} \mathrm{O}_{3}$, and $\mathrm{Mn}_{3} \mathrm{O}_{4}$ ) have aroused intense interest since they possess high theoretical capacities

${ }^{a}$ State Key Laboratory of Solidification Processing, Center for Nano Energy Materials, School of Materials Science and Engineering, Northwestern Polytechnical University, Xi'an 710072, China. E-mail: weib@udel.edu

${ }^{b}$ Department of Mechanical Engineering, University of Delaware, Newark, DE19716, USA

$\dagger$ Electronic supplementary information (ESI) available: Raman spectrum and TGA curve of the $\mathrm{MnO} / \mathrm{C}$ composite; TEM images of $\mathrm{MnO}_{2} / \mathrm{PPy}$; SEM images of $\mathrm{MnO}$; XPS spectra of $\mathrm{MnO} / \mathrm{C}$; EIS curves of the $\mathrm{MnO} / \mathrm{C}$ anode in the fresh state and after 100 cycles. EIS curves of $\mathrm{MnO} / \mathrm{C}, \mathrm{MnO}$ and $\mathrm{MnO}_{2}$ electrodes. Cycling performance of the $\mathrm{MnO} / \mathrm{C}$ anode at $500 \mathrm{~mA} \mathrm{~g}^{-1}$. See DOI: $10.1039 / \mathrm{c} 5$ ta02440d (for instance, $755 \mathrm{~mA} \mathrm{~h} \mathrm{~g}^{-1}$ for MnO, more than double that of graphite (372 $\left.\mathrm{mA} \mathrm{h}^{-1}\right)$ ), narrow voltage hysteresis, low cost, natural abundance, and non-toxicity. ${ }^{5}$ However, there are several hurdles when using $\mathrm{MnO}_{x}$ as anode materials, which include a low electric conductivity $\left(10^{-8}\right.$ to $\left.10^{-6} \mathrm{~S} \mathrm{~cm}^{-1}\right)$ and large volumetric change $(>170 \%)$ during the conversion reaction (i.e., charge/discharge processes) that result in poor cycling stability and inferior rate capability. ${ }^{7}$ To tackle these problems, two key strategies are noted: (1) reducing $\mathrm{MnO}_{x}$ size to the nanoscale region can not only accommodate the structural strains caused by $\mathrm{Li}^{+}$insertion/extraction, but also provide short ion/electron transport pathways and large specific surface areas for fast reaction kinetics; (2) compositing $\mathrm{MnO}_{x}$ with carbon can increase the electric conductivity and cushion the volume change of $\mathrm{MnO}_{x}$. Consequently, many studies have integrated the two strategies to prepare various $\mathrm{MnO}_{x} / \mathrm{C}$ nanocomposites by employing appropriate methods. ${ }^{7-27}$

Typically, powder-like $\mathrm{MnO}_{x} / \mathrm{C}$ nanocomposites require extra conductive additives, binders, and current collectors to constitute an electrode. The electrode fabrication includes complex and time-consuming slurry casting procedures. In contrast, an electrode in freestanding forms eliminates the use of electrochemical inactive components, e.g. binders, conductive additives, and/or current collectors, which account for more than $50 \mathrm{wt} \%$ of the electrode. When taking all of these components into account, the specific capacity of freestanding electrodes would be much more appealing. To date, the construction of freestanding nanostructured $\mathrm{MnO}_{x} / \mathrm{C}$ films is based on freestanding carbon scaffolds, such as CNT macro-films, ${ }^{7,28}$ compacted graphene films, ${ }^{29}$ 
and electrospun $\mathrm{CNF}$ fabrics ${ }^{30-33}$ with $\mathrm{MnO}_{x}$ deposits on the exterior surfaces of the carbon structures without encapsulation, which typically results in rapid degradation in cycling stability and limited $\mathrm{MnO}_{x}$ loading (13-51.7 wt\%). For example, Zhang et al. explored various methods to incorporate $\mathrm{MnO}_{x}$ nanostructures onto freestanding $\mathrm{CNF}$ fabrics, but the resultant $\mathrm{MnO}_{x} / \mathrm{CNF}$ nanocomposites exhibited a large discharge capacity fade of about $24 \%$ after 50 cycles. $^{30-32}$ In addition, it is noted that all of these reported freestanding materials have not experienced a long cycling test beyond 100 cycles, which presumably arises from the exposed $\mathrm{MnO}_{x}$ nanostructures on the carbon surfaces that cannot endure a long-term cycling. Fortunately, carbon coating is considered to be a simple, low-cost, and effective technique that is suitable for encapsulating transition metal oxide nanostructures with diverse dimensions including zero-dimensional (0D) nanoparticles, ${ }^{34}$ one-dimensional (1D) nanowires/nanorods/nanotubes, ${ }^{8-16}$ and two-dimensional (2D) nanoplates. ${ }^{17,18}$ It has been demonstrated that the cycle life of $\mathrm{MnO}_{x}$ electrodes can be extended due to a carbon layer coated on the surface of the $\mathrm{MnO}_{x}$ nanostructures. ${ }^{\mathbf{8} 34}$ Therefore, the cycling limitation of freestanding electrodes is expected to be overcome by using this simple technique.

In this work, we combine the advantages of freestanding electrodes and the carbon coating technique into a single entity. Our strategy starts with the synthesis of ultralong $\mathrm{MnO}_{2}$ nanowires, which can randomly entangle to form a flexible and freestanding $\mathrm{MnO}_{2}$ membrane. Then the freestanding $\mathrm{MnO}_{2}$ membrane was transformed into a freestanding electrode film of entangled coaxial $\mathrm{MnO} / \mathrm{C}$ nanowires through a facile in situ interfacial polymerization reaction of pyrrole monomers surrounding the $\mathrm{MnO}_{2}$ nanowires followed by a carbonization treatment, as schematically illustrated in Fig. 1 (details are in the Experimental section). Owing to the ultralong 1D nanostructure and the uniform carbon coating layer, the freestanding coaxial $\mathrm{MnO} / \mathrm{C}$ nanocomposite anode exhibits excellent lithium-storage performance in terms of specific capacity, rate capability and particularly cycling stability in addition to an extremely high MnO loading (80.2 wt\%).

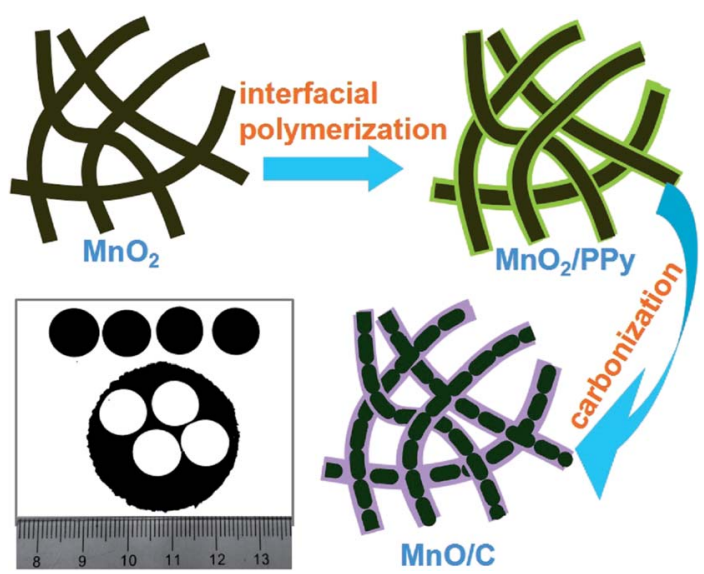

Fig. 1 Schematic illustration of synthesis of ultralong $\mathrm{MnO} / \mathrm{C}$ nanowires and a photograph of the freestanding electrodes punched from the freestanding $\mathrm{MnO} / \mathrm{C}$ membrane.

\section{Experimental section}

\subsection{Materials synthesis}

All of the chemical reagents were of analytical grade and were used as received without purification.

Synthesis of ultralong $\mathrm{MnO}_{2}$ nanowires. The ultralong $\mathrm{MnO}_{2}$ nanowires were synthesized according to ref. 38 with some modification. In a typical procedure, $2 \mathrm{mmol}$ of $\mathrm{MnSO}_{4} \cdot \mathrm{H}_{2} \mathrm{O}$, $3.5 \mathrm{mmol}$ of $\mathrm{KClO}_{3}$, and $3.5 \mathrm{mmol}$ of $\mathrm{CH}_{3} \mathrm{COOK}$ were dissolved in $35 \mathrm{~mL}$ of deionized water. Subsequently, $1.6 \mathrm{~mL}$ of $\mathrm{CH}_{3} \mathrm{COOH}$ was added into the above solution under magnetic stirring to form a homogeneous solution. The solution was transferred into a Teflon-lined stainless steel autoclave with a capacity of 50 $\mathrm{mL}$, which was then kept in a blast electric oven at $160{ }^{\circ} \mathrm{C}$ for 12 h. After naturally cooling down to room temperature, the brown precipitates were filtered and washed with deionized water several times, and finally dried at $80^{\circ} \mathrm{C}$ overnight. To fabricate a uniform membrane, a certain amount of $\mathrm{MnO}_{2}$ nanowires was dispersed in distilled water and then filtered by vacuum filtration using a $0.8 \mu \mathrm{m}$ porous filter paper.

Synthesis of ultralong $\mathrm{MnO} / \mathrm{C}$ hybrid nanowires. Typically, $100 \mathrm{mg}$ of the as-prepared ultralong $\mathrm{MnO}_{2}$ nanowires were dispersed in $20 \mathrm{~mL}$ of $0.1 \mathrm{M} \mathrm{HCl}$ solution under ultrasonication for $30 \mathrm{~min}$. Afterwards, $25 \mu \mathrm{L}$ of pyrrole monomers were added dropwise into the above suspension. The color of the suspension was observed to evolve from brown to black. The in situ reaction was maintained for $4 \mathrm{~h}$ to complete the polymerization process. The resulting black products were filtered and washed using ethanol and deionized water several times. To obtain a freestanding $\mathrm{MnO} / \mathrm{C}$ membrane, a $\mathrm{MnO}_{2} / \mathrm{PPy}$ membrane was prepared by vacuum filtration before the carbonization process. Then the as-prepared $\mathrm{MnO}_{2} / \mathrm{PPy}$ and $\mathrm{MnO}_{2}$ membranes were heated to $600{ }^{\circ} \mathrm{C}$ at a ramping rate of $2{ }^{\circ} \mathrm{C} \min ^{-1}$ under the protection of $\mathrm{N}_{2}$ gas flow, and maintained at this temperature for $2 \mathrm{~h}$.

\subsection{Structure characterization}

The phase structures were identified by X-ray powder diffraction analysis (XRD, X'Pert PRO MPD, Philips) with $\mathrm{Cu}-\mathrm{K} \alpha$ radiation $(\lambda=1.5418 \AA)$. The Raman spectrum was recorded on a Renishaw Invia RM200 (England) at room temperature in the spectral range of $200-2000 \mathrm{~cm}^{-1}$. The mass content of the carbon coating was determined using thermogravimetric analysis (TGA, TA instrument SDT-Q600). The morphologies and microstructures of the samples were observed on a field emission scanning electron microscope (FE-SEM, LEO-1530) and a high-resolution transmission electron microscope (HRTEM, FEI Tecnai $\mathrm{F}_{0 \mathrm{G}}{ }^{2}$ ). The surface chemistry of the nanocomposites was investigated using X-ray photoelectron spectroscopy (XPS, ESCALAB 250Xi, Thermo Scientific).

\subsection{Electrochemical measurements}

The electrochemical properties were measured using coin-type (CR2032) half cells. The working electrodes $(\Phi=13 \mathrm{~mm})$ were punched directly from the as-fabricated $\mathrm{MnO} / \mathrm{C}, \mathrm{MnO}$, and $\mathrm{MnO}_{2}$ membranes, which were directly used to assemble battery 
cells. The mass of the electrodes is about $1 \mathrm{mg} \mathrm{cm}^{-2}$. Coil cells were assembled with freestanding electrodes as the working electrodes, metal Li plates as the counter electrodes, Celgard 2320 as the separator, and a solution of $1 \mathrm{M} \mathrm{LiPF}_{6}$ in ethylene carbonate (EC)/dimethyl carbonate (DMC)/diethyl carbonate (DEC) (1:1:1 by volume) as the electrolyte in an argon-filled glovebox. A Solartron electrochemical workstation $(1260+1287$, England) was employed for obtaining cyclic voltammetry (CV) curves in the range of $0.005-3 \mathrm{~V}$ at a rate of $0.2 \mathrm{mV} \mathrm{s}^{-1}$ and electrochemical impedance spectra (EIS) in the frequency range of $100 \mathrm{kHz}$ to $50 \mathrm{mHz}$ at room temperature. The galvanostatic charge/discharge tests were carried out using a Land Battery Testing system (Land, China) at various current densities between the cut-off potentials of 0.01 and $2.50 \mathrm{~V} v s . \mathrm{Li} / \mathrm{Li}^{+}$.

\section{Results and discussion}

An ultralong 1D MnO nanostructure (length $>100 \mu \mathrm{m}$ ) is crucial to achieve the formation of flexible and robust freestanding $\mathrm{MnO} / \mathrm{C}$ membranes. Hence, it is imperative to maintain the unique ultralong nanostructure during the synthesis processes. A novel but facile method to synthesize ultralong $\mathrm{MnO} / \mathrm{C}$ coaxial nanowires is employed to avoid breakage of the ultralong $\mathrm{MnO}_{2}$ nanowires when coating carbon layers using a hydrothermal method (Fig. 1). ${ }^{\mathbf{1 4}}$

The core of this strategy is creating uniform PPy coatings on the ultralong $\mathrm{MnO}_{2}$ nanowire surfaces via in situ interfacial polymerization of pyrrole monomers, which is based on the redox reaction between pyrrole monomers and $\mathrm{MnO}_{2}$ because of the high oxidation potential of $\mathrm{MnO}_{2}\left(\mathrm{MnO}_{2}+4 \mathrm{H}^{+}+2 \mathrm{e} \rightarrow\right.$ $\left.\mathrm{Mn}^{2+}+2 \mathrm{H}_{2} \mathrm{O}, \varphi\left(\mathrm{MnO}_{2} / \mathrm{Mn}^{2+}\right)=1.23 \mathrm{~V}\right)$ for polymerizing pyrrole monomers. ${ }^{35,36}$ This process is totally different from conventional PPy preparation using other oxidants, such as $\mathrm{FeCl}_{3}{ }^{37}$ and $\mathrm{Na}_{2} \mathrm{~S}_{2} \mathrm{O}_{8}$, ${ }^{9}$ which would generate many individual PPy nanoparticles disconnected to $\mathrm{MnO}_{2}$. Due to the reactive $\mathrm{MnO}_{2}$ template, the formation of PPy can only occur at the pyrrole/ $\mathrm{MnO}_{2}$ interface, thus easily constructing a core-shell $\mathrm{MnO}_{2} / \mathrm{PPy}$ nanoconfiguration by controlling the pyrrole $/ \mathrm{MnO}_{2}$ ratio. Finally, freestanding membranes consisting of $\mathrm{MnO} / \mathrm{C}$ coaxial nanowires were obtained after a simple carbonization treatment. Fig. 1 also shows a digital image of the resulting MnO/C membrane, from which four freestanding electrodes were punched out without cracks, suggesting robust mechanical integrity of the membrane.

The as-prepared samples were first investigated using X-ray diffraction (XRD) to examine the phase structures and the resulting patterns are shown in Fig. 2. For the pristine $\mathrm{MnO}_{2}$ precursor, all diffraction peaks can be exclusively indexed to tetragonal $\alpha-\mathrm{MnO}_{2}$ (PDF\#81-1947). ${ }^{38}$ After the carbonization process at $600{ }^{\circ} \mathrm{C}$ for $2 \mathrm{~h}$ in a flowing nitrogen atmosphere, the $\alpha-\mathrm{MnO}_{2}$ phase was converted to MnO. As shown in the patterns of the annealed products, the diffraction peaks at $2 \theta$ around $35.0,40.7,58.8,70.3$, and $73.9^{\circ}$ can be readily indexed to (111), (200), (220), (311), and (222) reflections of the cubic $\mathrm{MnO}$ (PDF\#07-0230). No other diffraction peaks are detected, indicating a high purity of the products. In order to confirm the presence of carbon coatings in the $\mathrm{MnO} / \mathrm{C}$ nanocomposites, the
Raman spectrum was recorded. As shown in Fig. S1, $\dagger$ the two broad peaks at 1355 and $1583 \mathrm{~cm}^{-1}$ can be assigned to the D and $\mathrm{G}$ bands of carbon. ${ }^{17}$ The high intensity of the $\mathrm{D}$ band suggests disordered carbon structures that possess a large amount of defects. In addition, the fundamental peaks at 567 and $642 \mathrm{~cm}^{-1}$ are characteristic of the $\mathrm{Mn}-\mathrm{O}$ vibration modes. ${ }^{\mathbf{9} 21,34}$ The carbon content in the $\mathrm{MnO} / \mathrm{C}$ nanocomposites was determined using thermogravimetric analysis (TGA), as shown in Fig. S2, $\uparrow$ the carbon content is calculated to be about $19.8 \mathrm{wt} \%$.

The morphology and microstructure of the freestanding $\mathrm{MnO}_{2}$ and $\mathrm{MnO} / \mathrm{C}$ membranes were characterized using FESEM and TEM. Fig. 3(a) and (b) show the top-view SEM images of the $\mathrm{MnO}_{2}$ membrane (inset shows the optical photograph). The membrane is purely composed of randomly oriented ultralong and straight nanowires with smooth surfaces. The $1 \mathrm{D}$ nanowires possess a length of hundreds of micrometers and an average diameter of approximately $100 \mathrm{~nm}$, corresponding to a high aspect ratio of $>1000$. The nanowires are entangled with each other to construct a robust membrane structure with high porosity and flexibility. A typical TEM image of the $\mathrm{MnO}_{2}$ nanowires is exhibited in Fig. 3(c). The HRTEM image in Fig. 3(d) shows distinct lattice fringes of $0.49 \mathrm{~nm}$ in spacing, which agrees well with the interplanar distances of (200) planes of $\alpha-\mathrm{MnO}_{2}$. The corresponding SAED pattern (inset) exhibits well-defined diffraction spots that can be indexed to the $\alpha-\mathrm{MnO}_{2}$ structure. The HRTEM and SAED results also indicate the high quality single crystalline nature of the $\alpha-\mathrm{MnO}_{2}$ nanowires.

After in situ interfacial polymerization of PPy using the $\mathrm{MnO}_{2}$ nanowires as oxidant supports, the surface of the $\mathrm{MnO}_{2}$ nanowires was uniformly coated with PPy layers (Fig. S3†). The subsequent annealing process leads to PPy carbonization and the $\mathrm{MnO}_{2}$ to $\mathrm{MnO}$ phase transformation. Fig. 4(a-c) and $\mathrm{S} 4 \dagger$ show the typical morphology of the $\mathrm{MnO} / \mathrm{C}$ and $\mathrm{MnO}$ membranes. The large-scale panoramic view (Fig. 4(a)) indicates that the $\mathrm{MnO} / \mathrm{C}$ membrane (Fig. 1) possesses a porous architecture consisting of interconnected nanowires. The ultralong nanostructure after annealing is well maintained without breakage (Fig. 4(b and c) and $\mathrm{S} 4 \dagger$ ). As shown in Fig. 4(d), each $\mathrm{MnO}$ nanowire is enveloped by a uniformly coated carbon layer,

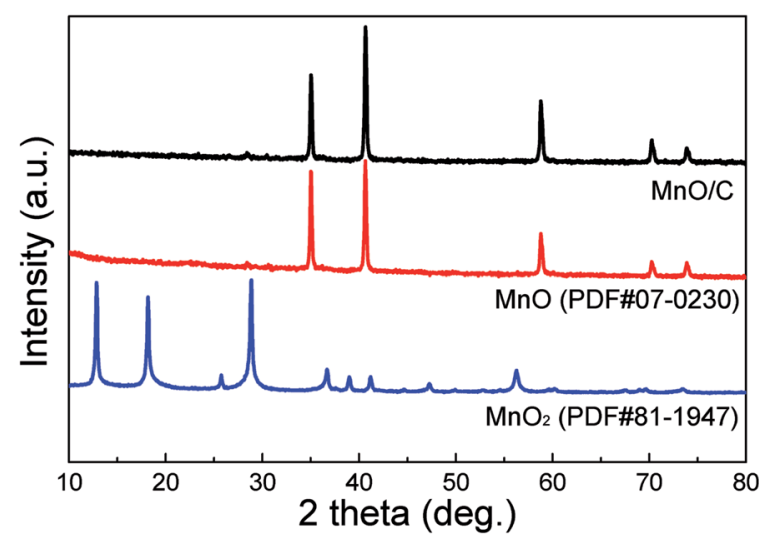

Fig. 2 XRD patterns of $\mathrm{MnO} / \mathrm{C}, \mathrm{MnO}$ and $\mathrm{MnO}_{2}$ samples. 

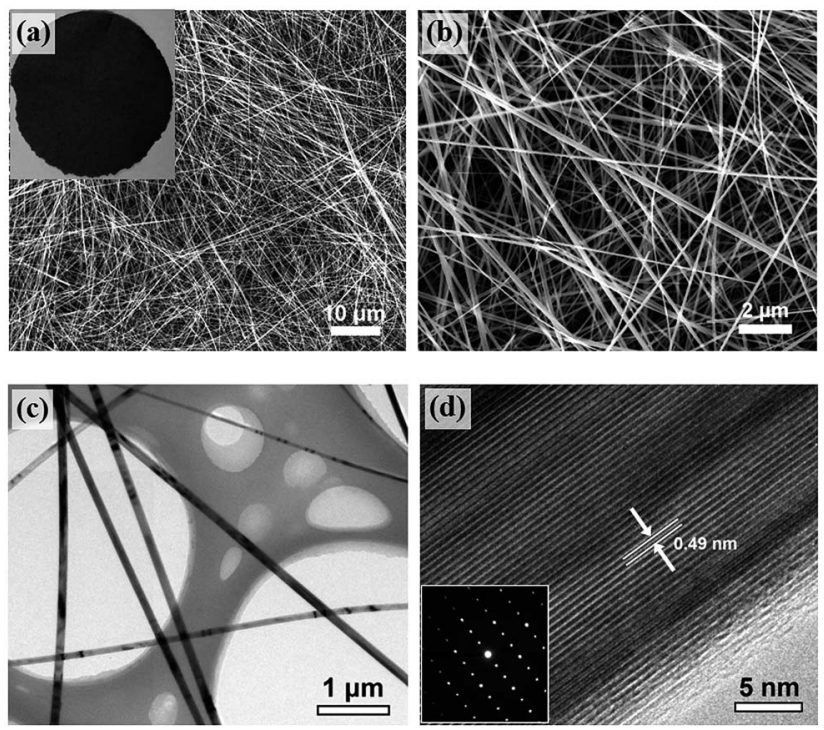

Fig. 3 (a-b) SEM images of $\alpha-M_{n} \mathrm{O}_{2}$ nanowires. Inset shows the optical photograph of the membrane. (c) TEM and (d) HRTEM images of $\alpha-\mathrm{MnO}_{2}$ nanowires. Inset shows the corresponding SAED pattern.

constructing a unique coaxial configuration. The diameter of the coaxial nanowires is in the $80-100 \mathrm{~nm}$ range and the thickness of the carbon coating layer is about $15 \mathrm{~nm}$ (Fig. 4(e)). The HRTEM image in Fig. 4(f) displays clear lattice fringes with a spacing of $0.22 \mathrm{~nm}$, which corresponds to the interplanar distances of the (200) planes of the cubic MnO phase.

XPS was employed to analyze the surface elements and their electronic states of the $\mathrm{MnO} / \mathrm{C}$ nanocomposites (Fig. S5 $\dagger$ ). The survey spectrum (Fig. S5(a)†) confirms the presence of Mn, O, C, and $\mathrm{N}$ elements in the product with no trace of impurities. The high-resolution Mn 2p doublet (Fig. S5(b) †) with two peaks located at $641.5 \mathrm{eV}$ for $\mathrm{Mn} 2 \mathrm{p}_{3 / 2}$ and $653.2 \mathrm{eV}$ for $\mathrm{Mn} 2 \mathrm{p}_{1 / 2}$ is characteristic of $\mathrm{MnO}^{34,39}$ The oxidation state of $\mathrm{Mn}$ in the $\mathrm{MnO} / \mathrm{C}$ nanocomposites can be determined by analyzing the Mn 3s spectrum. As shown in Fig. S5(c), $\uparrow$ the spin energy separation of $5.78 \mathrm{eV}$ demonstrates a Mn valence of $+2 .{ }^{40}$ The $\mathrm{C}$ 1s peak (Fig. S5(d) †) can be fitted into four components centered at 284.6, 285.5, 286.4, and $288.1 \mathrm{eV}$, representing C-C, $\mathrm{C}-\mathrm{N}, \mathrm{C}-\mathrm{O}-\mathrm{C}$, and $\mathrm{C}-\mathrm{O}$ bonds, respectively. ${ }^{21,38,41}$ The $\mathrm{N} 1 \mathrm{~s}$ peak (Fig. S5(e)†) can be resolved into two peaks centered at 398.3 and $400.4 \mathrm{eV}$, which correspond to hexagonal pyridinic-N (N6) and pentagonal pyrrolic-N (N5), respectively. ${ }^{42-44}$ A high N6/N5 ratio of 1.26 indicates that a large portion of $\mathrm{N}$ atoms within the pyrrole rings is converted to pyridinic- $\mathrm{N}$ during the annealing process. More importantly, the $\mathrm{sp}^{2}$ hybridized pyridinic-N can enhance the electronic conductivity of the carbon structure, ${ }^{42,44,45}$ which is beneficial to improving the electrochemical performance of the $\mathrm{MnO} / \mathrm{C}$ nanocomposites.

The as-prepared $\mathrm{MnO} / \mathrm{C}$ nanocomposite membranes were directly used as freestanding anodes for LIBs to investigate their Li-ion storage properties. The electrochemical behavior is first studied using the cyclic voltammetry (CV) method. Fig. 5(a) shows the CV curves of the initial four cycles at a scan rate of 0.2 $\mathrm{mV} \mathrm{s}^{-1}$. In the first cathodic sweep, the sharp reduction peak below $0.5 \mathrm{~V}$ corresponds to the reduction of $\mathrm{Mn}^{2+}$ to $\mathrm{Mn}^{0}$ and the formation of solid electrolyte interface (SEI) films..$^{18,34,39}$ From the second cycle, the reduction peak shifts to approximately $0.36 \mathrm{~V}$, which is a reversible phase transformation resulting from the formation of metallic $\mathrm{Mn}$ and $\mathrm{Li}_{2} \mathrm{O}$. The observed peak centered at $1.35 \mathrm{~V}$ in the anodic sweep is attributed to the oxidation of $\mathrm{Mn}^{0}$ to $\mathrm{Mn}^{2+}$. The reversible conversion reaction can be written as follows:

$$
\mathrm{MnO}+2 \mathrm{Li}^{+}+2 \mathrm{e}^{-} \leftrightarrow \mathrm{Mn}+\mathrm{Li}_{2} \mathrm{O}
$$

In addition, the $\mathrm{CV}$ curves after the first cycle overlapped well, indicating high reversibility and good electrochemical
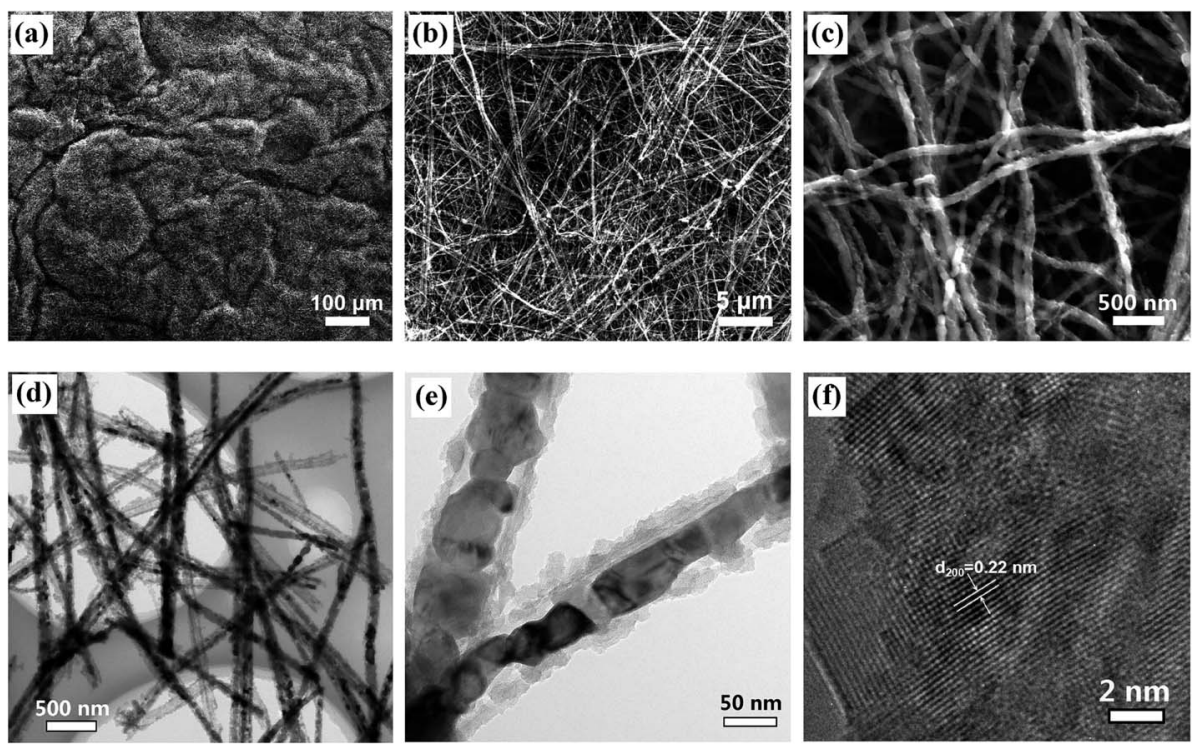

Fig. 4 (a-c) SEM images of $\mathrm{MnO} / \mathrm{C}$ at different magnifications. (d-e) TEM images of $\mathrm{MnO} / \mathrm{C}$ nanowires. (f) HRTEM image of MnO nanocrystals. 
stability of the freestanding $\mathrm{MnO} / \mathrm{C}$ anode. Fig. 5(b) shows the charge/discharge voltage profiles of the $\mathrm{MnO} / \mathrm{C}$ anode at a current density of $100 \mathrm{~mA} \mathrm{~g}^{-1}$. In the first discharge process, a long voltage plateau at $0.2 \mathrm{~V}$, which is related to the reduction of $\mathrm{Mn}^{2+}$ to $\mathrm{Mn}$, can be observed, and the plateau shifts to about 0.5 $\mathrm{V}$ in the second and the onward discharge processes. During the subsequent charge processes, the sloped plateau in the 1.1-1.5 $\mathrm{V}$ range is associated with the re-oxidation of $\mathrm{Mn}$ to $\mathrm{Mn}^{2+}$. These results are consistent with the $\mathrm{CV}$ analysis. It is important to note that the first discharge and charge specific capacity are 1001 and $683 \mathrm{~mA} \mathrm{~h} \mathrm{~g} \mathrm{~g}^{-1}$, respectively, revealing an initial Coulombic efficiency of $68.2 \%$ that is common for transition metal oxide anodes. The irreversible capacity loss can be ascribed to the inevitable formation of SEI films on the surface of the anode and some irreversible side reactions of $\mathrm{Li}^{+}$with oxygen-contained functional groups and some special sites in
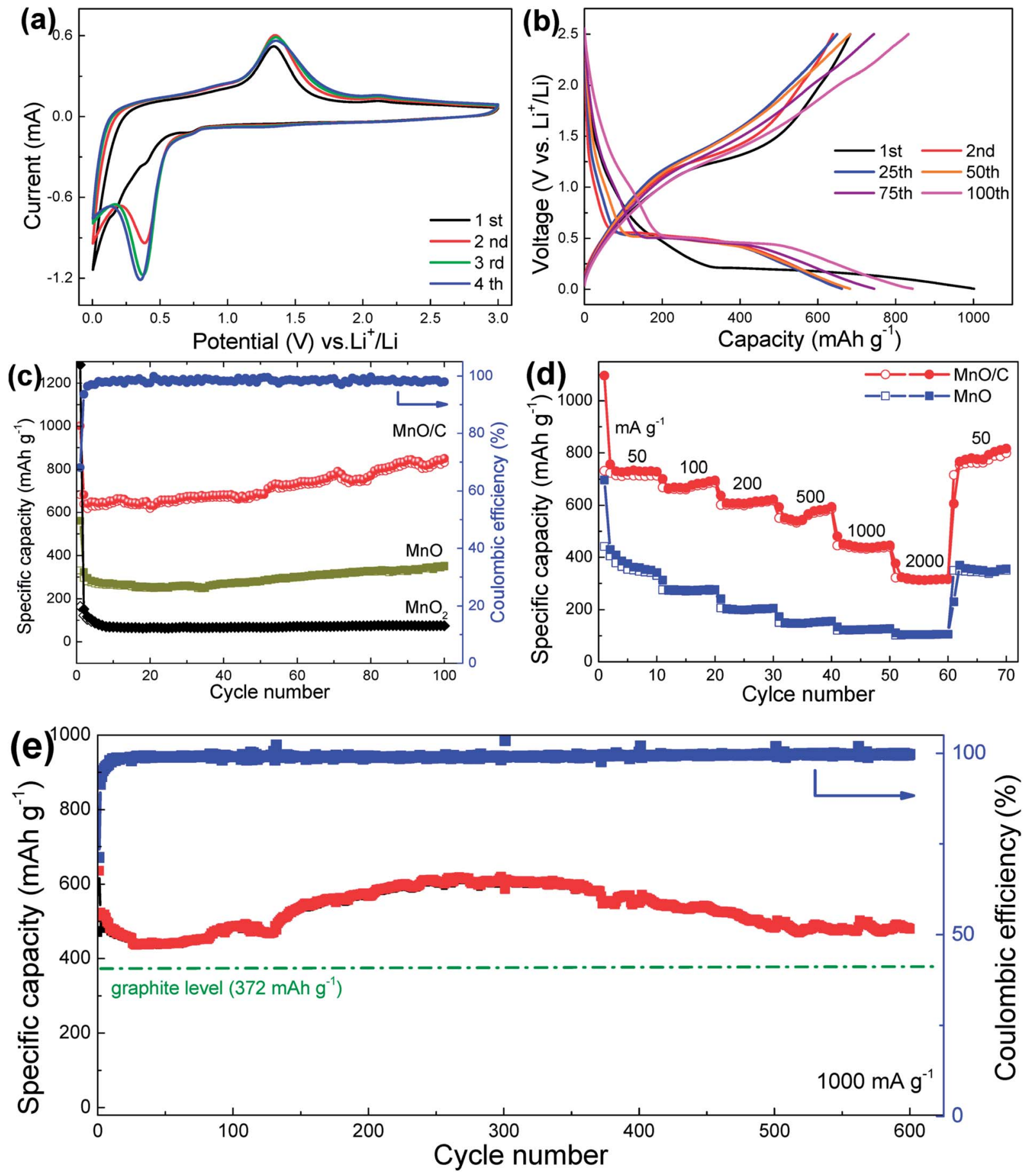

Fig. 5 (a) $\mathrm{CV}$ curves and (b) galvanostatic charge/discharge profiles of $\mathrm{MnO} / \mathrm{C}$ anodes. (c) Cycling performance of $\mathrm{MnO}_{2}, \mathrm{MnO}$ and $\mathrm{MnO} / \mathrm{C}$ anodes at a current density of $100 \mathrm{~mA} \mathrm{~g}^{-1}$. (d) Rate capability of $\mathrm{MnO}$ and $\mathrm{MnO} / \mathrm{C}$ anodes. (e) Long-term cycling performance of the $\mathrm{MnO} / \mathrm{C}$ anode at a current density of $1000 \mathrm{~mA} \mathrm{~g}^{-1}$. 
the vicinity of residual $\mathrm{H}$ atoms in the carbon structure. ${ }^{43} \mathrm{It}$ should be noted that the initial Coulombic efficiency of the $\mathrm{MnO} / \mathrm{C}$ anode is much higher than that of control samples, $\mathrm{MnO}(58.9 \%)$ and $\mathrm{MnO}_{2}$ (12.9\%), indicating a better electrochemical utilization of $\mathrm{MnO}$ enhanced by the conductive carbon coating. Fig. 5(c) compares the cycling performance of the three freestanding anodes. Notably, the $\mathrm{MnO} / \mathrm{C}$ nanocomposites exhibit a reversible capacity of $832 \mathrm{~mA} \mathrm{~h} \mathrm{~g}^{-1}$ after 100 cycles at a current density of $100 \mathrm{~mA} \mathrm{~g}^{-1}$, which is much higher than those of $\mathrm{MnO}$ (349 $\mathrm{mA} \mathrm{h} \mathrm{g}^{-1}$ ) and $\mathrm{MnO}_{2}$ (75 $\mathrm{mA} \mathrm{h} \mathrm{g}^{-1}$ ). The specific capacity is also higher than the initial values and the theoretical

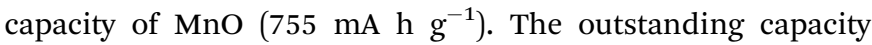
retention is believed to result from the uniform carbon coating, which renders improved conversion reaction kinetics and higher reaction activities. The improved kinetics of the MnO/C anode upon cycling are mainly attributed to the reduction of the charge-transfer resistance confirmed by electrochemical impedance spectra (EIS) analysis (Fig. S6†). The lower chargetransfer resistance allows a faster Li-reaction with $\mathrm{MnO}$, which enables $\mathrm{Mn}^{2+}$ to be re-oxidized to a higher oxidation state. ${ }^{22}$ This phenomenon can also be observed in the charge voltage profiles, as shown in Fig. 5(b), the sloped plateau at around 2.1 $\mathrm{V}$ becomes more broader upon cycling, indicating an everincreasing capacity and higher Li-reaction activities that can generate a reversible capacity higher than the theoretical value of MnO.

In addition to the superior capacity, the freestanding $\mathrm{MnO} / \mathrm{C}$ anode also presents good rate capability. As shown in Fig. 5(d), the $\mathrm{MnO} / \mathrm{C}$ anode exhibits significantly enhanced rate performance compared to the bare $\mathrm{MnO}$ anode. When tested at different current densities of 50 (0.07 C), 100 (0.13 C), 200 (0.26 C), 500 (0.66 C), 1000 (1.32 C), and $2000 \mathrm{~mA} \mathrm{~g}^{-1}$ (2.65 C), the nanocomposite anode can deliver average reversible capacities of $731,678,614,556,440$, and $315 \mathrm{~mA} \mathrm{~h} \mathrm{~g}^{-1}$, respectively. After the high-rate cycling at $2000 \mathrm{~mA} \mathrm{~g}^{-1}$, the capacity increases to $810 \mathrm{~mA} \mathrm{~h} \mathrm{~g}{ }^{-1}$ when the current density is recovered to $50 \mathrm{~mA}$ $\mathrm{g}^{-1}$, further implying the excellent reversibility of the $\mathrm{MnO} / \mathrm{C}$ anode. The better rate capability of the $\mathrm{MnO} / \mathrm{C}$ anode can be ascribed to the carbon coating, which offers high conductivity for rapid electron collection and migration during the high-rate cycling. The ultralong 1D nanowires further help the conductive carbon coatings to promote long-range charge transference and the membrane offers a porous structure for efficient electrolyte ingress and diffusion throughout the electrode. In addition, the coaxial nanoscale structure can shorten the ion/electron transport distance to boost the reaction kinetics. The EIS comparison among the three anodes (Fig. S7†) clearly demonstrates that the $\mathrm{MnO} / \mathrm{C}$ anode has the smallest charge-transfer resistance compared with the control anodes, indicating better reaction kinetics.

To further investigate the long-cycle stability of the $\mathrm{MnO} / \mathrm{C}$ anodes operated at high-rates, the $\mathrm{MnO} / \mathrm{C}$ anodes were measured at high current densities of 500 and $1000 \mathrm{~mA} \mathrm{~g}^{-1}$ for 400 and 600 cycles, respectively, as shown in Fig. S8† and 5(e). It demonstrates that the $\mathrm{MnO} / \mathrm{C}$ anode can deliver a specific capacity of $480 \mathrm{~mA} \mathrm{~h} \mathrm{~g}^{-1}$ after 600 charge/discharge cycles at $1000 \mathrm{~mA} \mathrm{~g}^{-1}$ with a Coulombic efficiency of over $98 \%$ (initial efficiency: $71.3 \%$ ), similarly, a specific capacity of $597 \mathrm{~mA} \mathrm{~h}^{-1}$ is retained after 400 cycles at $500 \mathrm{~mA} \mathrm{~g}^{-1}$. The remarkable highrate cycling stability can primarily be ascribed to the typical surface carbon coating, which functions as a resilient barrier to accommodate the volume expansion/contraction of $\mathrm{MnO}$ during the lithiation/delithiation processes and to preclude the agglomeration of the coaxial nanostructures upon cycling. In addition, the freestanding architecture can provide high mechanical strength to maintain the structural integrity of the electrode.

In addition to the overall excellent electrochemical performance of the freestanding $\mathrm{MnO} / \mathrm{C}$ anode, it is worth mentioning that the capacity results reported here are calculated based on the total mass of the freestanding electrodes. As mentioned earlier, the electrochemically inactive components of extra binders, conductive additives and in particular current collectors account for at least $50 \mathrm{wt} \%$ of a conventional electrode fabricated with powder-like nanomaterials. When taking all of these inactive components into consideration, the freestanding $\mathrm{MnO} / \mathrm{C}$ nanocomposite would be much more fascinating in terms of gravimetric energy density and electrode fabrication (time saving). In addition, the specific capacity of the $\mathrm{MnO} / \mathrm{C}$ anode during the high-rate 600-cycle test at $1000 \mathrm{~mA}$ $\mathrm{g}^{-1}$ (1.32 C, Fig. 5(e)) is not only much higher than the theoretical value $\left(372 \mathrm{~mA} \mathrm{~h} \mathrm{~g}^{-1}\right)$ of the commercial graphite anode, but also superior to other freestanding $\mathrm{MnO}_{x} / \mathrm{C}$ nanocomposites, such as $\mathrm{MnO}_{x} /$ sing-walled CNT (437 $\mathrm{mA} \mathrm{h} \mathrm{g}{ }^{-1}$ at $800 \mathrm{~mA} \mathrm{~g}^{-1}$ ), ${ }^{28} \mathrm{Mn}_{3} \mathrm{O}_{4} /$ super-aligned CNT (465 $\mathrm{mA} \mathrm{h} \mathrm{g}^{-1}$ at $\left.1 \mathrm{C}\right){ }^{7}$ $\mathrm{MnO}_{2}$ /graphene (305 $\mathrm{mA} \mathrm{h} \mathrm{g}^{-1}$ at $\left.800 \mathrm{~mA} \mathrm{~g}^{-1}\right),{ }^{29} \mathrm{MnO}_{x} / \mathrm{CNF}(420$ $\mathrm{mA} \mathrm{h} \mathrm{g}{ }^{-1}$ at $\left.500 \mathrm{~mA} \mathrm{~g}^{-1}\right),{ }^{31}$ and $\mathrm{MnO}_{x} / \mathrm{CNF}\left(255 \mathrm{~mA} \mathrm{~h} \mathrm{~g}^{-1}\right.$ at 500 $\left.\mathrm{mA} \mathrm{g}^{-1}\right){ }^{32}$ Together with the facile synthesis procedures, the long-term cycling performance promises the freestanding $\mathrm{MnO} /$ $\mathrm{C}$ nanocomposite to be a potential anode material for practical applications.

\section{Conclusions}

Freestanding membranes consisting of ultralong $\mathrm{MnO} / \mathrm{C}$ coaxial nanowires have successfully been fabricated using a hydrothermal method followed by in situ interfacial polymerization of PPy and a carbonization process. The ultralong 1D nanostructure and the uniform carbon coating collectively enable the as-fabricated freestanding $\mathrm{MnO} / \mathrm{C}$ anodes to exhibit excellent lithium-storage properties in terms of specific capacity, rate capability, and particularly cycling stability. The electrochemical evaluations indicate that the freestanding $\mathrm{MnO} / \mathrm{C}$ anode can deliver a high specific capacity of $832 \mathrm{~mA} \mathrm{~h}$ $\mathrm{g}^{-1}$ at $100 \mathrm{~mA} \mathrm{~g}^{-1}$ after 100 cycles. More significantly, even after a long-term 600-cycle test at a high current rate of $1000 \mathrm{~mA} \mathrm{~g}^{-1}$, the anode retains a reversible capacity of $480 \mathrm{~mA} \mathrm{~h} \mathrm{~g}{ }^{-1}$. The remarkable electrochemical performance demonstrates that the freestanding $\mathrm{MnO} / \mathrm{C}$ nanocomposite holds great potential as a promising anode material for advanced LIBs. Furthermore, the present synthesis strategy paves a new avenue for fabricating freestanding LIB electrodes based on other transition metal oxide nanostructures. 


\section{Acknowledgements}

The authors acknowledge the financial support of this work from the National Natural Science Foundation of China (51402236, 53102219 and 51472204), the National Natural Science Foundation of Shannxi Province (2015JM5180), the Fundamental Research Funds for the Central Universities (3102014JCQ01020), and the Program of Introducing Talents of Discipline to Universities (B08040), the Specialized Research Fund for the Doctoral Program of Higher Education of China (20136102140001 and 20136102120024). BQW is grateful for the financial support from the US National Science Foundation (1067960).

\section{References}

1 T.-H. Kim, J.-S. Park, S. K. Chang, S. Choi, J. H. Ryu and H.-K. Song, Adv. Energy Mater., 2012, 2, 860-872.

2 M. Armand and J.-M. Tarascon, Nature, 2008, 451, 652-657. 3 V. Etacheri, R. Marom, R. Elazari, G. Salitra and D. Aurbach, Energy Environ. Sci., 2011, 4, 3243-3262.

4 M. V. Reddy, G. V. S. Rao and B. V. R. Chowdari, Chem. Rev., 2013, 113, 5364-5457.

5 L. Ji, Z. Lin, M. Alcoutlabi and X. Zhang, Energy Environ. Sci., 2011, 4, 2682-2699.

6 P. Poizot, S. Laruelle, S. Grugeon, L. Dupont and J. Tarascon, Nature, 2000, 407, 496-499.

7 S. Luo, H. Wu, Y. Wu, K. Jiang, J. Wang and S. Fan, J. Power Sources, 2014, 249, 463-469.

8 X. Li, S. Xiong, J. Li, X. Liang, J. Wang, J. Bai and Y. Qian, Chem.-Eur. J., 2013, 19, 11310-11319.

9 X. Gu, J. Yue, L. Chen, S. Liu, H. Xu, J. Yang, Y. Qian and X. Zhao, J. Mater. Chem. A, 2015, 3, 1037-1041.

10 B. Sun, Z. Chen, H.-S. Kim, H. Ahn and G. Wang, J. Power Sources, 2011, 196, 3346-3349.

11 X. Li, Y. Zhu, X. Zhang, J. Liang and Y. Qian, RSC Adv., 2013, 3, 10001-10006.

12 L. Su, Y. Zhong, J. Wei and Z. Zhou, RSC Adv., 2013, 3, 90359041.

13 C. Wang, L. Yin, D. Xiang and Y. Qi, ACS Appl. Mater. Interfaces, 2012, 4, 1636-1642.

14 G.-L. Xu, Y.-F. Xu, H. Sun, F. Fu, X.-M. Zheng, L. Huang, J.-T. Li, S.-H. Yang and S.-G. Sun, Chem. Commun., 2012, 48, 8502-8504.

15 Y. Ding, C. Wu, H. Yu, J. Xie, G. Cao, T. Zhu, X. Zhao and Y. Zeng, Electrochim. Acta, 2011, 56, 5844-5848.

16 L. Li, C. Nan, J. Lu, Q. Peng and Y. Li, Chem. Commun., 2012, 48, 6945-6947.

17 X. Zhang, Z. Xing, L. Wang, Y. Zhu, Q. Li, J. Liang, Y. Yu, T. Huang, K. Tang and Y. Qian, J. Mater. Chem., 2012, 22, 17864-17869.

18 Y. Sun, X. Hu, W. Luo and Y. Huang, J. Mater. Chem., 2012, 22, 19190-19195.

19 A. L. M. Reddy, M. M. Shaijumon, S. R. Gowda and P. M. Ajayan, Nano Lett., 2009, 9, 1002-1006.

20 H. Xia, M. Lai and L. Lu, J. Mater. Chem., 2010, 20, 68966902.
21 K. Zhang, P. Han, L. Gu, L. Zhang, Z. Liu, Q. Kong, C. Zhang, S. Dong, Z. Zhang and J. Yao, ACS Appl. Mater. Interfaces, 2012, 4, 658-664.

22 Y. Sun, X. Hu, W. Luo, F. Xia and Y. Huang, Adv. Funct. Mater., 2013, 23, 2436-2444.

23 H. Wang, L.-F. Cui, Y. Yang, H. Sanchez Casalongue, J. T. Robinson, Y. Liang, Y. Cui and H. Dai, J. Am. Chem. Soc., 2010, 132, 13978-13980.

24 Y. Mai, D. Zhang, Y. Qiao, C. Gu, X. Wang and J. Tu, J. Power Sources, 2012, 216, 201-207.

25 W.-M. Chen, L. Qie, Y. Shen, Y.-M. Sun, L.-X. Yuan, X.-L. Hu, W.-X. Zhang and Y.-H. Huang, Nano Energy, 2013, 2, 412418.

26 C. Chae, J. H. Kim, J. M. Kim, Y.-K. Sun and J. K. Lee, J. Mater. Chem., 2012, 22, 17870-17877.

27 Z. Li, N. Liu, X. Wang, C. Wang, Y. Qi and L. Yin, J. Mater. Chem., 2012, 22, 16640-16648.

28 J. Qin, Q. Zhang, Z. Cao, X. Li, C. Hu and B. Wei, Nano Energy, 2013, 2, 733-741.

29 A. Yu, H. W. Par, A. Davies, D. C. Higgins, Z. Chen and X. Xiao, J. Phys. Chem. Lett., 2011, 2, 1855-1860.

30 L. Ji and X. Zhang, Electrochem. Commun., 2009, 11, 795-798.

31 L. Ji, A. J. Medford and X. Zhang, J. Mater. Chem., 2009, 19, 5593-5601.

32 Z. Lin, L. Ji, M. D. Woodroof and X. Zhang, J. Power Sources, 2010, 195, 5025-5031.

33 B. Liu, X. Hu, H. Xu, W. Luo, Y. Sun and Y. Huang, Sci. Rep., 2013, 4, 4299.

34 Y. Xiao, X. Wang, W. Wang, D. Zhao and M. Cao, ACS Appl. Mater. Interfaces, 2014, 6, 2051-2058.

35 J.-G. Wang, B. Wei and F. Kang, RSC Adv., 2014, 4, 199-202.

36 J.-G. Wang, Y. Yang, Z.-H. Huang and F. Kang, Electrochim. Acta, 2014, 130, 642-649.

37 J. Li, L. Cui and X. Zhang, Appl. Surf. Sci., 2010, 256, 43394343.

38 B. Lan, L. Yu, T. Lin, G. Cheng, M. Sun, F. Ye, Q. Sun and J. He, ACS Appl. Mater. Interfaces, 2013, 5, 7458-7464.

39 Y. Xia, Z. Xiao, X. Dou, H. Huang, X. Lu, R. Yan, Y. Gan, W. Zhu, J. Tu, W. Zhang and X. Tao, ACS Nano, 2013, 7, 7083-7092.

40 M. Toupin, T. Brousse and D. Bélanger, Chem. Mater., 2004, 16, 3184-3190.

41 L. Qie, W. Chen, H. Xu, X. Xiong, Y. Jiang, F. Zou, X. Hu, Y. Xin, Z. Zhang and Y. Huang, Energy Environ. Sci., 2013, 6, 2497-2504.

42 D. Nan, Z.-H. Huang, R. Lv, L. Yang, J.-G. Wang, W. Shen, Y. Lin, X. Yu, L. Ye, H. Sun and F. Kang, J. Mater. Chem. A, 2014, 2, 19678-19684.

43 L. Qie, W.-M. Chen, Z.-H. Wang, Q.-G. Shao, X. Li, L.-X. Yuan, X.-L. Hu, W.-X. Zhang and Y.-H. Huang, Adv. Mater., 2012, 24, 2047-2050.

44 W. H. Shin, H. M. Jeong, B. G. Kim, J. K. Kang and J. W. Choi, Nano Lett., 2012, 12, 2283-2288.

45 H. M. Jeong, J. W. Lee, W. H. Shin, Y. J. Choi, H. J. Shin, J. K. Kang and J. W. Choi, Nano Lett., 2011, 11, 2472-2477. 